\title{
Interpretation of various slip modes on a plate boundary based on laboratory and numerical experiments
}

\author{
Shingo Yoshida ${ }^{1}$, Aitaro Kato ${ }^{1,2}$, Naoyuki Kato ${ }^{1}$, and Masao Nakatani ${ }^{1}$ \\ ${ }^{1}$ Earthquake Research Institute, University of Tokyo, Tokyo 113-0032, Japan \\ ${ }^{2}$ Institute for Frontier Research on Earth Evolution, Japan Marine Science and Technology Center, Yokohama 236-0001, Japan
}

(Received December 16, 2003; Revised July 9, 2004; Accepted July 12, 2004)

\begin{abstract}
This paper discusses various slip modes on a plate boundary on the basis of a two-degree-of-freedom block-spring model and large-scale biaxial experiments, including a new experimental result on afterslip. We conducted slip experiments using large granite blocks with a pre-existing fault surface of $100 \mathrm{~cm}$ in length. Velocity-strengthening friction was given over a half of the fault length by inserting a thin Teflon sheet, while the other half retained velocity-weakening friction of the bare rock surface. Under a loading at a constant velocity, dynamic stick-slip repeated on the velocity-weakening region, causing afterslip on the velocity-strengthening region. The velocitystrengthening region experienced small coseismic slip as well, with the magnitude decreasing with the distance from the velocity-weakening region. The behaviors observed in the laboratory experiments were quantitatively simulated by a two-degree-of-freedom block-spring model, in which two blocks (Block 1 and Block 2) are connected by a liner spring and driven by a slowly moving driver. The friction on each block was assumed to obey rate and state dependent friction law. When $a-b$ was assumed to be negative for Block 1, and positive for Block 2, afterslip occurred at Block 2. This model can also reproduce wide spectrum of slip modes by adjusting frictional parameters. Key words: Rate- and state-dependent friction law, afterslip, asperity.
\end{abstract}

\section{Introduction}

Recently various slip modes have been observed on a plate boundary, such as coseismic slip at asperity, episodic aseismic slip, and afterslip. Nagai et al. (2001) showed that one of asperities that ruptured in the 1968 Tokachi-oki earthquake (M 7.9) coincides with the asperity which ruptured in the 1994 Sanriku-haruka-oki earthquake (M 7.5). This suggests that asperities are conserved over earthquake cycles, which may indicate that different slip mode reflects the different properties of the interface fixed to the locality.

The Geographical Survey Institute of Japan detected a slow slip event in the Tokai region, in central Japan, based on the Global Positioning System (GPS) data (Ozawa et al., 2002; Sagiya, 2003). GPS sites in the western Tokai district started digressing from their secular displacement trends, in late 2000. Ozawa et al. (2002) estimated slip motion on the plate boundary in this area. The estimated seismic moment from March to August 2001 of this slow event was $1.2 \times 10^{19}$ Nm. This slow slip event continues as of November 2003. Moreover, Kimata et al. (2001) suggested that similar aseismic slip events occurred episodically in the last 30 years in this region based on the analysis of the vertical movements by leveling and line length change by electro-optical distance meter (EDM). Sagiya (2003) pointed out that episodic aseismic slip events having a different duration time have been discovered in many locations (Hirose et al., 1999; Dragert et al., 2001; Freymueller et al., 2001; Lowry et al., 2001;

Copy right (c) The Society of Geomagnetism and Earth, Planetary and Space Sciences (SGEPSS); The Seismological Society of Japan; The Volcanological Society of Japan; The Geodetic Society of Japan; The Japanese Society for Planetary Sciences; TERRAPUB.
Ozawa et al., 2002). The duration times in the Bungo Channel (Hirose et al., 1999) and the Tokai district (Ozawa et al., 2002) are on the order of one year, but on the other hand, the duration in Cascadia is about a week (Dragert et al., 2001), and there exist silent events with durations on the order of one hour. Thus, the mode of subduction slip seems to constitute a continuous spectrum from steady continuous slip to fast dynamic events. A straightforward interpretation may be ascribing this to velocity dependence of friction, which can be anywhere between strongly negative to strongly positive.

Another important observation is the inverse relationship between coseismic and postseismic slip, with less afterslip occurring in areas of larger coseismic slip. Marone et al. (1991) summarized characteristics of afterslip mainly based on observation of earthquakes on the San Andreas fault. Afterslip on the San Andreas fault is restricted to the upper $4 \mathrm{~km}$, and little coseismic slip occurs within the sediments above $4-5 \mathrm{~km}$. Analysis of GPS observation has shown that afterslip occurred in a deeper region than asperity that ruptured during the main event for the 1994 Sanriku-harukaoki, Japan, eathquake (Yagi et al., 2003) and for the 1999 Izimit, Turkey earthquake (Reilinger et al., 2000). The afterslip following the 1997 Kronotsyky, Kamchatka, earthquake occurred near the downdip edge of the coseismic rupture and extended laterally away from it (Bürgmann et al., 2001).

These observations suggest the importance of interaction between adjacient regions with different fault properties. That recognition has been a mainstay of earthquake theory and simulation based on the rate- and state-dependent friction law since Tse and Rice (1986) performed simulations explaining the variation of seismic slip with depth at the San 


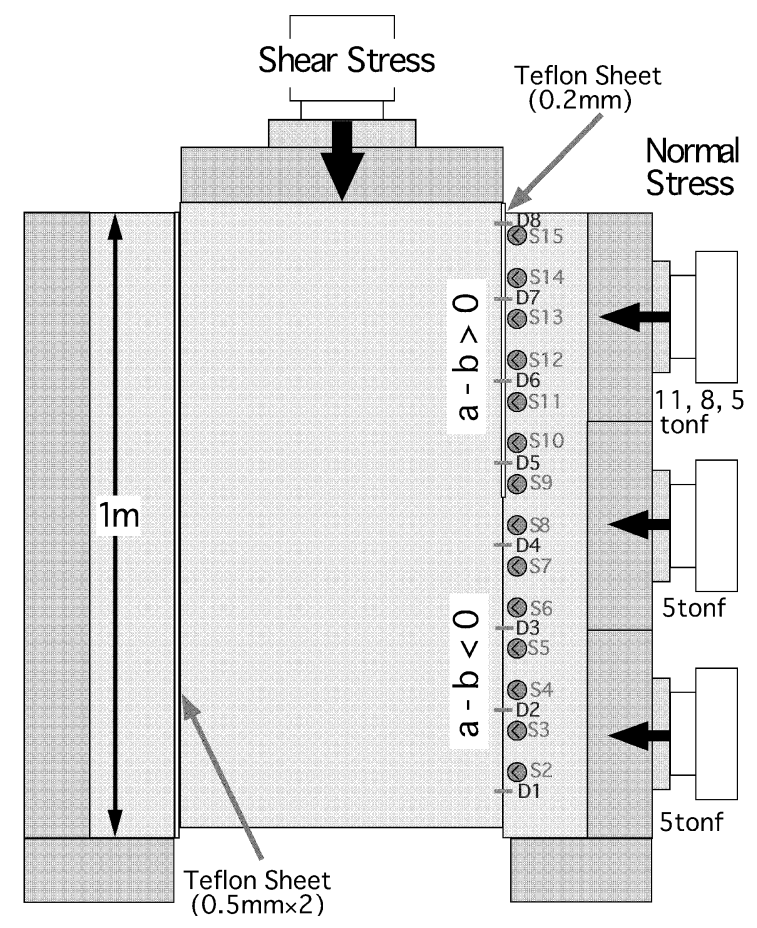

Fig. 1. Diagram of apparatus and sample assembly (map view). The sliding surface is $100 \mathrm{~cm}$ in length by $10 \mathrm{~cm}$ in width. 8 displacement sensors (D1-D8) are mounted on the top face along the fault, and 14 strain gauges (S2-S15) are mounted on the bottom face. A thin Teflon sheet is inserted along half section of the fault resulting in velocity-strengthening.

Andreas fault. That kind of modeling was extended to subduction by Stuart (1988) and Kato and Hirasawa (1997). Recently many researchers have performed three-dimensional simulations (e.g., Rice, 1993). In the present paper, we attempt to explain the interaction using a simple model because it may be sometimes easier to understand essential behavior by intuition on the basis of a simple model. The minimum system that can directly deal with interaction between different frictional regions is the system consisting of two regions with different frictional properties. Yoshida and Kato (2003) discussed various slip modes in terms of a twodegree-of-freedom block-spring model. In this framework, we add a result of laboratory experiment on afterslip using large granite blocks with a pre-existing fault having velocitystrengthening and velocity weakening regions. And then we attempt to reproduce quantitatively the experimental result in a numerical experiment using a two-degree-of-freedom block-spring model.

\section{Laboratory Experiment using a Large-scale Bi- axial Apparatus}

Figure 1 shows the biaxial apparatus and assembly of Inada granite blocks, in which slip occurs along two preexisting large faults, each $100 \mathrm{~cm}$ in length by $10 \mathrm{~cm}$ in width. Normal load was applied with three independent actuators so that we can produce heterogeneous distribution of normal stress along the long fault (Yoshida and Kato, 2001). Stick-slip occurred as the inner block was pushed at a fixed load point velocity of $0.064 \mu \mathrm{m} / \mathrm{s}$. Even if the loading forces applied by the three actuators are set to be equal, the normal stress has a heterogeneous distribution as a result of geomet- ric roughness with a long wavelength of the fault surface. By adjusting the normal force distribution, we can control the intensity of the heterogeneity.

As we focus on the interaction between different frictional property regions distributed on one fault (target fault), friction on the other fault was reduced by inserting two Teflon sheets with a thickness of $0.5 \mathrm{~mm}$ each, between which sliding occurred at a uniformly low friction. In this system, the three granite blocks were set horizontally.

Eight displacement sensors (D1-D8) of eddy current type were mounted on the top faces along the target sliding surface at $130 \mathrm{~mm}$ intervals in order to observe the local slip displacement. The overall frequency response of this displacement measuring system including the sensor and amplifier was flat from DC to $20 \mathrm{kHz}$. Local shear stress was monitored with the 14 shear strain gauges (S2-S15) mounted on the bottom faces of the outer block along the target sliding surface at $65 \mathrm{~mm}$ intervals in order to observe the strain as a function of time and position.

A thin Teflon sheet with a thickness of $0.2 \mathrm{~mm}$ was inserted along the half of the length of the target fault to give the velocity-strengthening friction $(a-b>0)$ to this section. Dieterich and Kilgore (1994) reported that Teflon on steel polished surface has positive $a-b$. The other half section has negative $a-b$, and acts as an asperity where dynamic slip occurs. The time histories of the local shear strains and displacements at a sampling frequency of $10 \mathrm{~Hz}$ are shown in Figs. 2(a) and (b). The normal forces were set to be 5, 5, and 11 tonf, resulting in the normal stress in the velocity-strengthening region of 2.7 $\mathrm{MPa}$, and that in the velocity-weakening region of 1.5 MPa. Later, we compare test with different normal stress distributions. In the velocity-weakening region, dynamic slip (D1D4) occurs accompanied with dynamic stress drop (S2-S6). Changes in S7 and S8 are small since the coupling in this area is weak because of the waveness of the fault surface. In the velocity-strengthening region, shear stress (S9-S15) is increased abruptly by the coseismic slip in the adjacent velocity-weakening region, and then afterslip follows (D5D8) gradually releasing the stress. Preslip occurred at the asperity (D2 and D3 in Fig. 2(c)), and the dynamic slip started from D3 as shown in the $500 \mathrm{kHz}$ sampling records (Fig. 2(d)). No preslip occurred in the velocity-strengthening region. At D5 located in the velocity-strengthening region close to the asperity, remarkable coseismic dynamic slip occurred, but coseismic slip becomes less important compared with afterslip as the distance from asperity increases. This is in accordance with the analysis of the afterslip of the 1994 Sanriku-haruka-oki earthquake by Yagi et al. (2003). They reported that the afterslip of the 1994 Sanriku-haruka-oki earthquake occurred in a region adjacent to the asperity that ruptured during the main event.

\section{Numerical Experiment using a Two-degree-of- freedom Block-spring Model}

Figure 3 shows a two degree-of-freedom block model as in Nussbaum and Ruina (1987), Huang and Turcotte (1990), and Yoshida and Kato (2003). Block 1 with a bottom area of $S_{1}$ and Block 2 with $S_{2}$ are connected by a liner spring with spring constant $K_{12}$ and driven by a driver slowly moving 


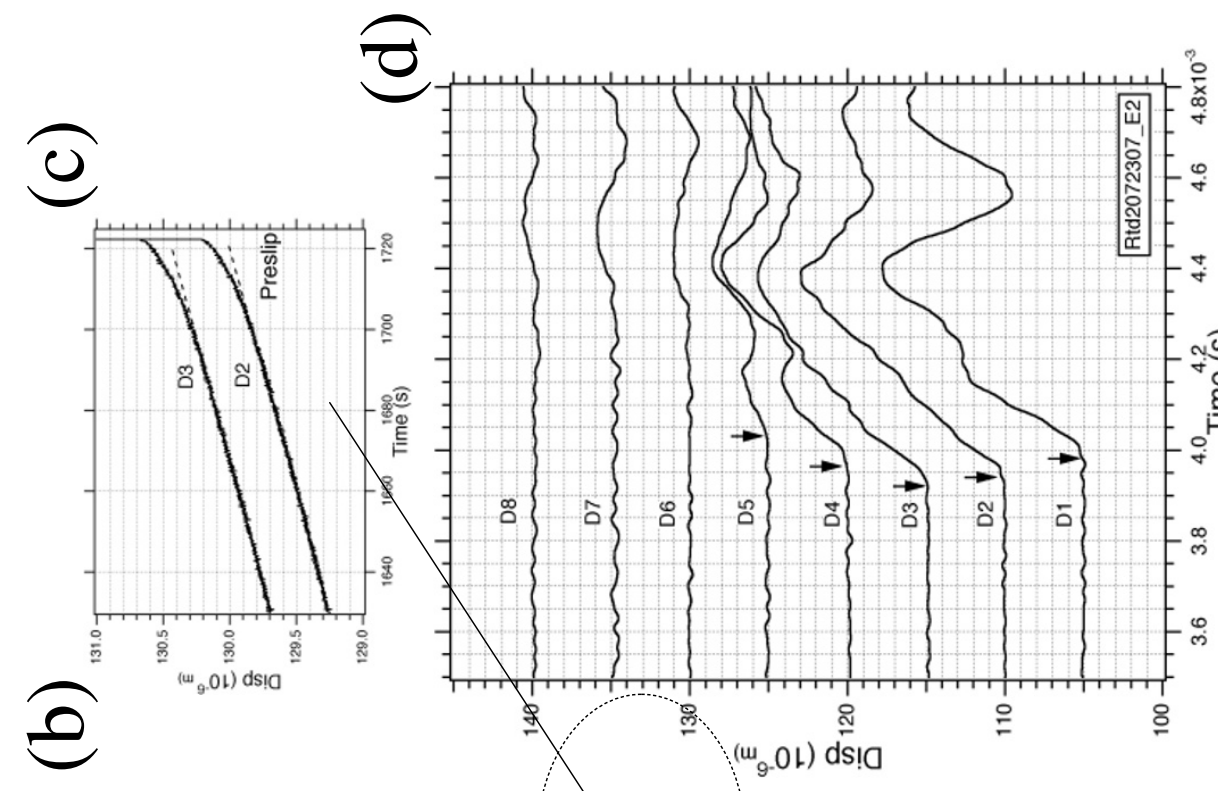

:

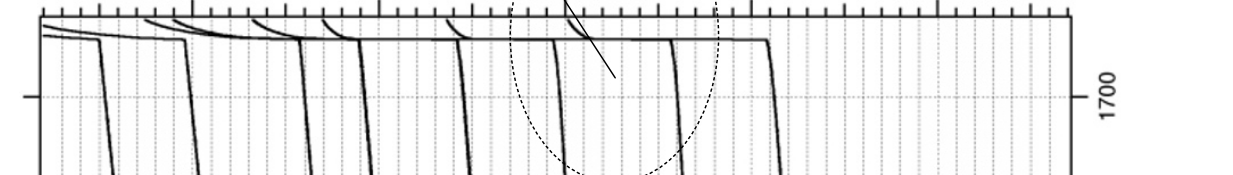

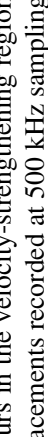

苛

:

这
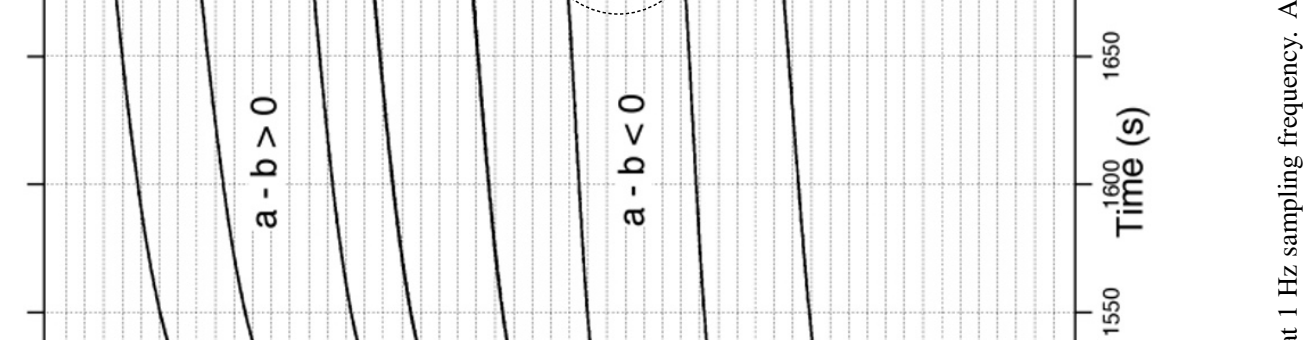

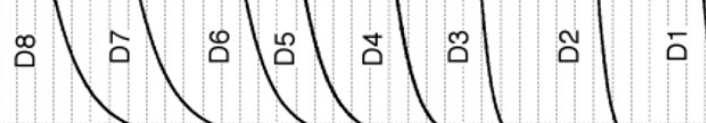
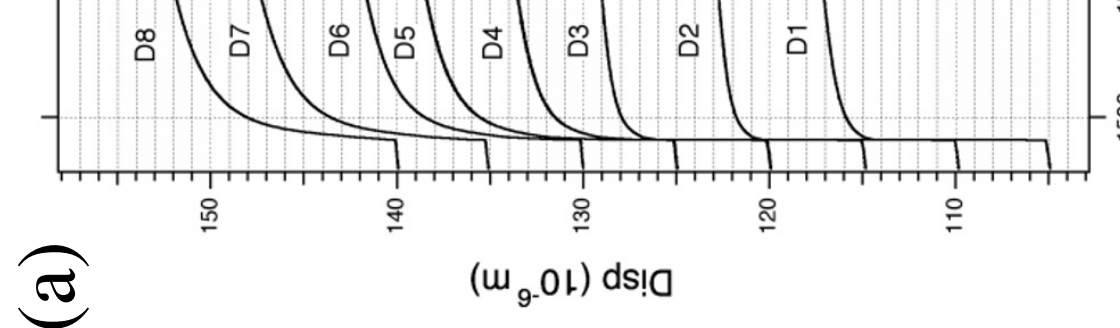

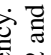

产会

竞 苛

信 完

촌

馬

这

它

产

这

$2 \frac{0}{2}$

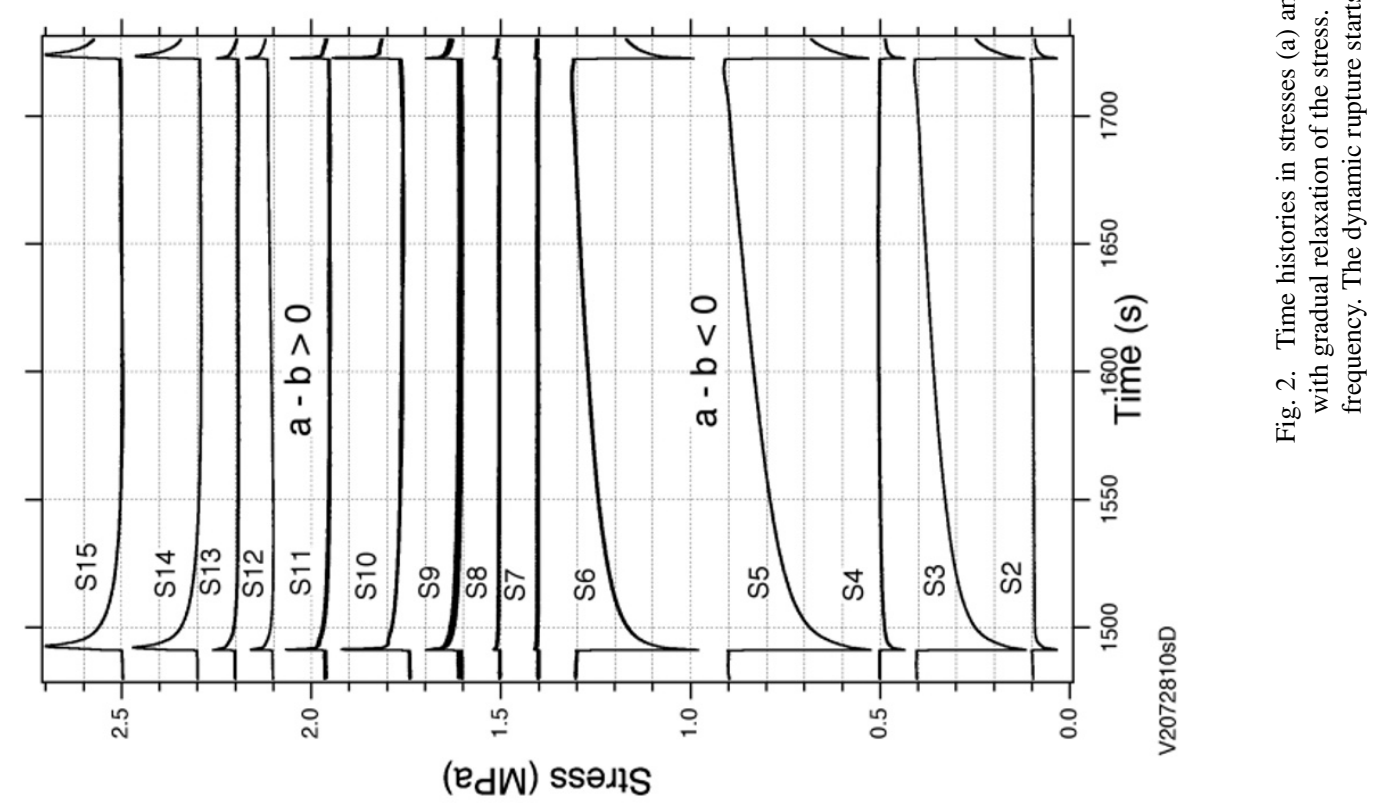




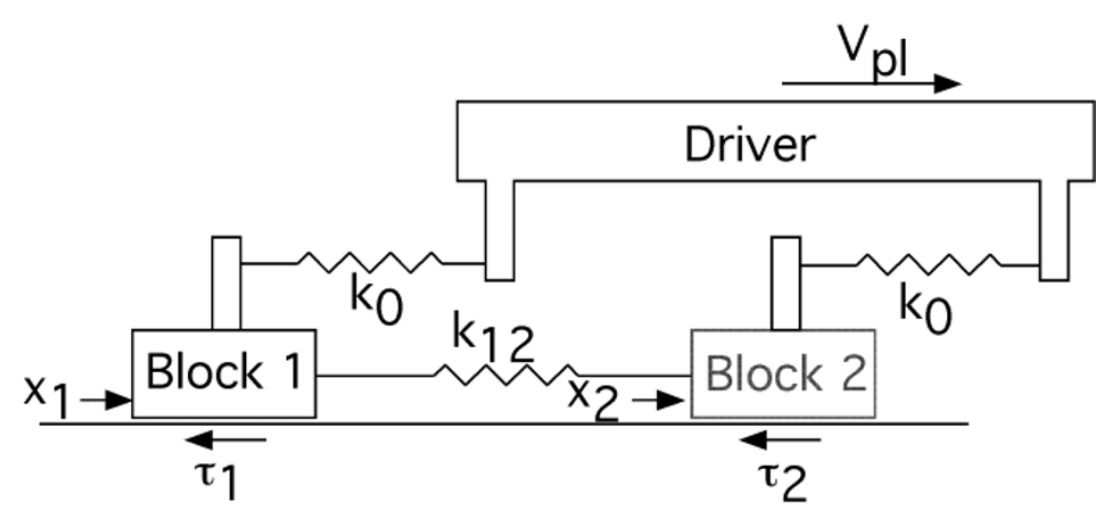

Fig. 3. Two degree-of-freedom block-spring model.

at a rate $V_{p l}$. Each block is connected to the driver with a spring having a spring constant $K_{0}$. The equations of motion are written as

$$
\begin{aligned}
& M_{1} \ddot{x}_{1}=K_{0}\left(V_{p l} t-x_{1}\right)+K_{12}\left(x_{2}-x_{1}\right)-\tau_{1} S_{1} \\
& M_{2} \ddot{x}_{2}=K_{0}\left(V_{p l} t-x_{2}\right)-K_{12}\left(x_{2}-x_{1}\right)-\tau_{2} S_{2}
\end{aligned}
$$

where $M_{i}$ and $x_{i}(i=1,2)$ are the mass and the position coordinate of each block, respectively, and $\tau_{i}$ is the shear friction on each block. Assuming the two block have the same bottom area $\left(S_{1}=S_{2}\right)$, and the same mass surface density $\left(m=M_{1} / S_{1}=M_{2} / S_{2}\right)$, we can write

$$
\begin{aligned}
& m \ddot{x}_{1}=k_{0}\left(V_{p l} t-x_{1}\right)+k_{12}\left(x_{2}-x_{1}\right)-\tau_{1} \\
& m \ddot{x}_{2}=k_{0}\left(V_{p l} t-x_{2}\right)-k_{12}\left(x_{2}-x_{1}\right)-\tau_{2}
\end{aligned}
$$

where $k_{0}=K_{0} / S_{i}, k_{12}=K_{12} / S_{i}$. If the two blocks have different bottom areas, the coupling elastic constants $K_{12} / S_{i}$ for the two blocks are different, and interaction from a larger block to a smaller block becomes more significant than the reverse interaction. In our simulation, we assume the both blocks have the same bottom areas for simplification.

A rate- and state-dependent friction law (Dieterich, 1979; Ruina, 1983) is assumed. We use the "slip law" version for state evolution.

$$
\begin{aligned}
\tau_{i} & =\sigma_{n}\left(\mu_{i}^{*}+a_{i} \ln \left(V_{i} / V^{*}\right)+b_{i} \ln \left(\theta_{i} / \theta^{*}\right)\right) \\
\dot{\theta}_{i} & =-\frac{V \theta_{i}}{L_{i}} \ln \left(\frac{V \theta_{i}}{L_{i}}\right)
\end{aligned}
$$

where $\sigma_{n}$ is the normal stress, $\theta$ is the state variable, $a_{i}, b_{i}$, $L_{i}(i=1,2)$ are the frictional parameters. $\mu^{*}$ and $\theta^{*}$ are the steady state values at $V^{*}$, which is chosen as $V_{p l}$. When Block 1 is locked, the equation of motion for Block 2 can be written as

$$
m \ddot{x}_{2}=\left(k_{0}+k_{12}\right)\left(\frac{k_{0} V_{p l}}{k_{0}+k_{12}} t-x_{2}\right)-\tau_{2}+\text { const } .
$$

This means that the situation is equivalent to that Block 2 is connected with spring of $k_{0}+k_{12}$ and driven by a driver moving at $k_{0} V_{p l} /\left(k_{0}+k_{12}\right)$. If $a_{i}-b_{i}<0$ and

$$
k_{c}=\left(B_{i}-A_{i}\right) / L_{i}>k_{0}+k_{12}
$$

where $A_{i}=\sigma_{n} a_{i}, B_{i}=\sigma_{n} b_{i}$, the slip of the $i^{\prime}$ th block becomes unstable, leading to instability without a trigger from the other block. If $a_{i}-b_{i}<0$ and

$$
k_{c}=\left(B_{i}-A_{i}\right) / L_{i}<k_{0}+k_{12}
$$

the $i^{\prime}$ th block is conditionally stable (Scholz, 1990).

In numerical simulation, we assume frictional parameters of Block 1 and the spring constants, $k_{0}, k_{12}$, so that Block 1 acts as an asperity where dynamic instability occurs. For Block $2, a-b$ is assumed to be positive.

The mass surface density of the block $m$, driver rate $V_{p l}$, spring constant $k$, and normal stresses $\sigma_{n}$ are assumed to be the same as those of the laboratory experiments. The assumed parameters are $m=1400 \mathrm{~kg} / \mathrm{m}^{2}, V_{p l}=0.064 \mu \mathrm{m} / \mathrm{s}$, $k_{0}+k_{12}=0.0175 \mathrm{MPa} / \mu \mathrm{m}, \sigma_{n}=1.5 \mathrm{MPa}$ for Block 1 , and $\sigma_{n}=2.7 \mathrm{MPa}$ for Block 2. The spring constants depend on the stiffness of the apparatus. As for frictional parameters and $k_{12} / k_{0}$, we searched for values which can explain quantitatively the laboratory experimental results in trial and error manner. The obtained frictional parameters are $a_{1}=0.00587, b_{1}=0.01174, L_{1}=0.15 \mu \mathrm{m}, a_{2}=0.0111$, $b_{2}=0.0037, L_{2}=2 \mu \mathrm{m}$, and $k_{12} / k_{0}=3 / 2$. The obtained values of $L$ may be larger than local $L$ at a point of rock specimen in the laboratory experiments. $L$ of block corresponds to a characteristic slip distance needed for evolution of state of the whole bottom surface of the block. Values of $b_{2}$ and $L_{2}$ for Block 2 (corresponding to Teflon inserted region) are not strongly constrained. Even when we assumed $b_{2}=0$, ( $L_{2}$ has no meaning in this case, $)$ the resultant behavior was not significantly changed if the value of $a_{2}-b_{2}$ was set to be the same. Figure 4(a) shows a result of the numerical simulation. Afterslip occurs at Block 2 having a positive $a-b$ (velocity strengthening), as a result of relaxation of a stress perturbation (e.g., Marone et al., 1991; Perfettini and Avouca, 2004). When the dynamic slip occurs at the adjacent asperity (Block 1), abrupt stress loading occurs at Block 2. Afterslip follows gradually releasing the stress. The rupture cycle of Block 2 has no locked stage. If Block 2 had locked stage during an interseismic period, the loading rate of Block 1 would be lower. Figure 4(b) shows stress and displacement averaged over positive $a-b$ region, and those for negative $a-b$ region in the laboratory experiment. The numerical experiment result reproduces the amount of stress change, slip and the recurrence time observed in the laboratory experiment very well. Usual numerical simulations of earthquake cycle on a plate boundary provide stress history, however, the calculated stress cannot be compared with the measured one. In contrast, the present paper attempted to directly compare calculated stress and displacement with the 

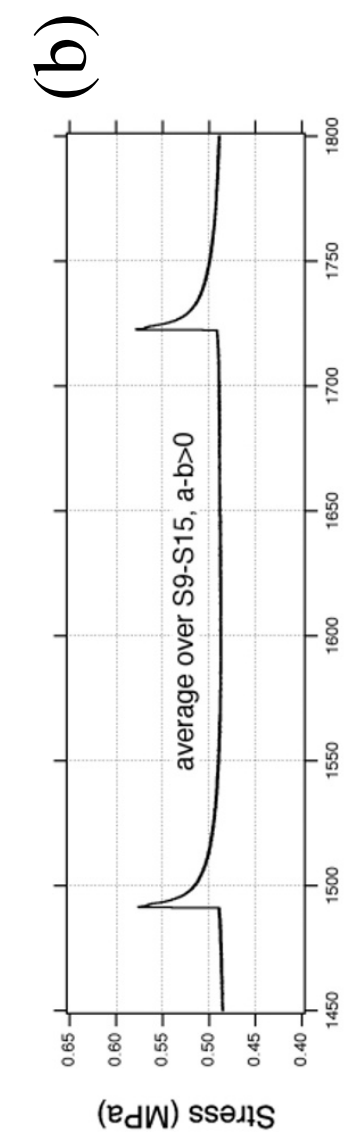

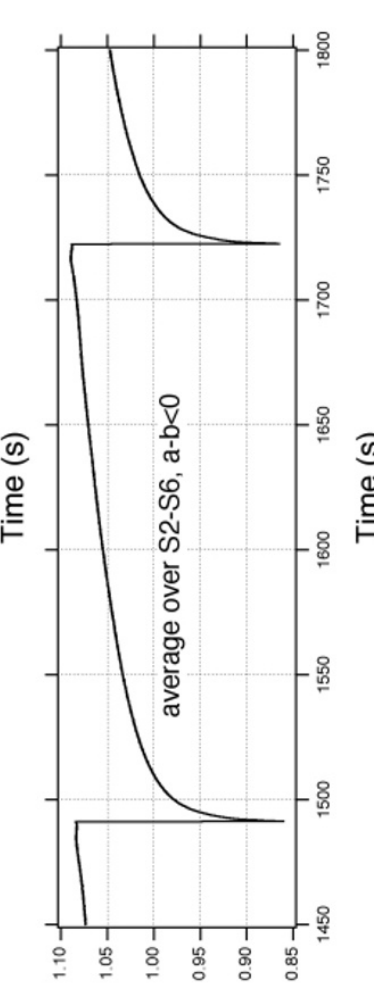

(edW) ssants

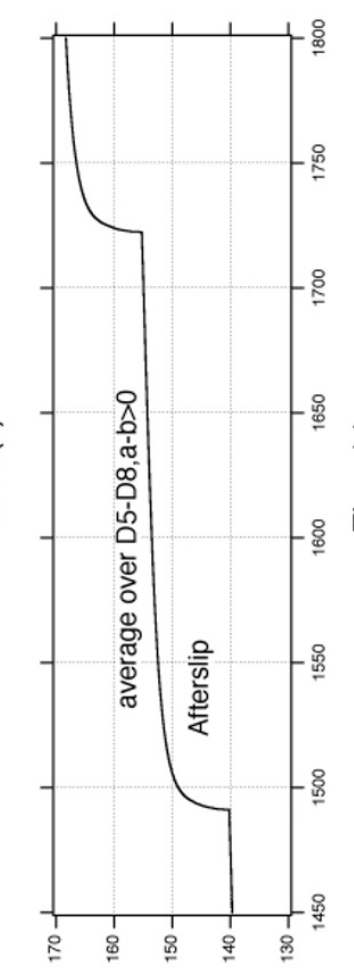

$\left(\mathrm{u}_{9-} \mathrm{O} \mathrm{l}\right) \cdot \mathrm{ds} \mathrm{C}$

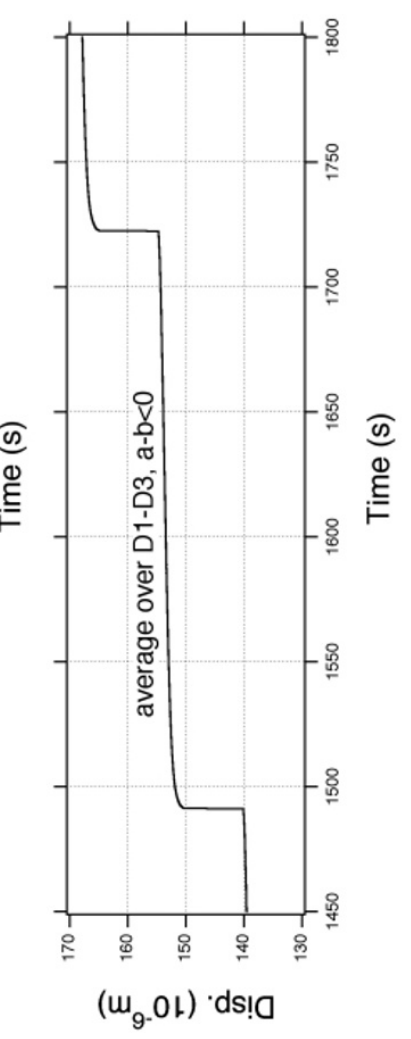

$\overbrace{0}^{0}$
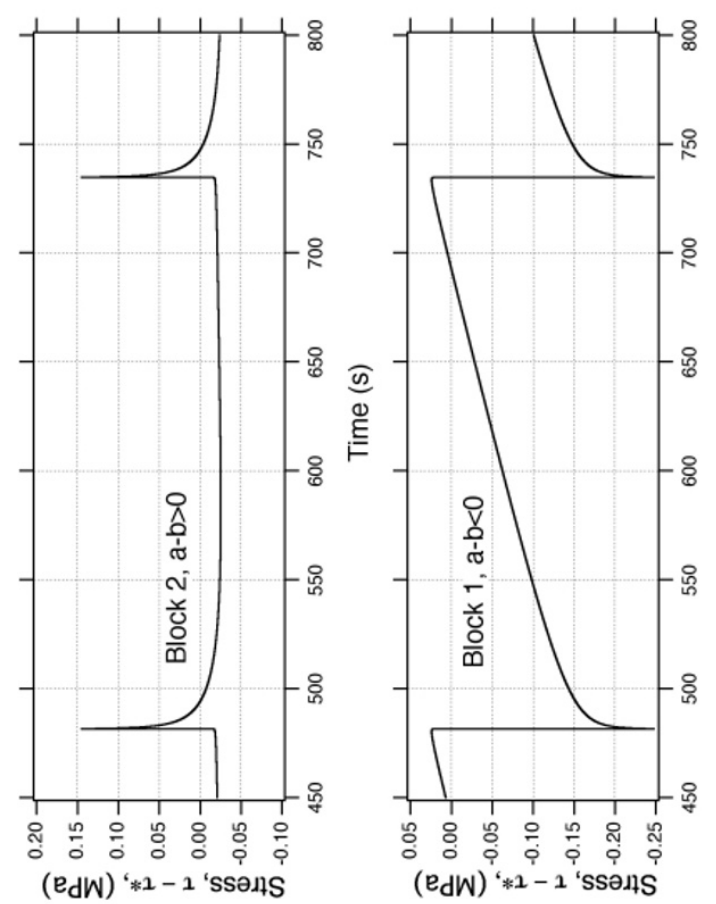

$\left(e_{\mathrm{dW}}\right)$ ‘ $* 1-1$ 'ssans
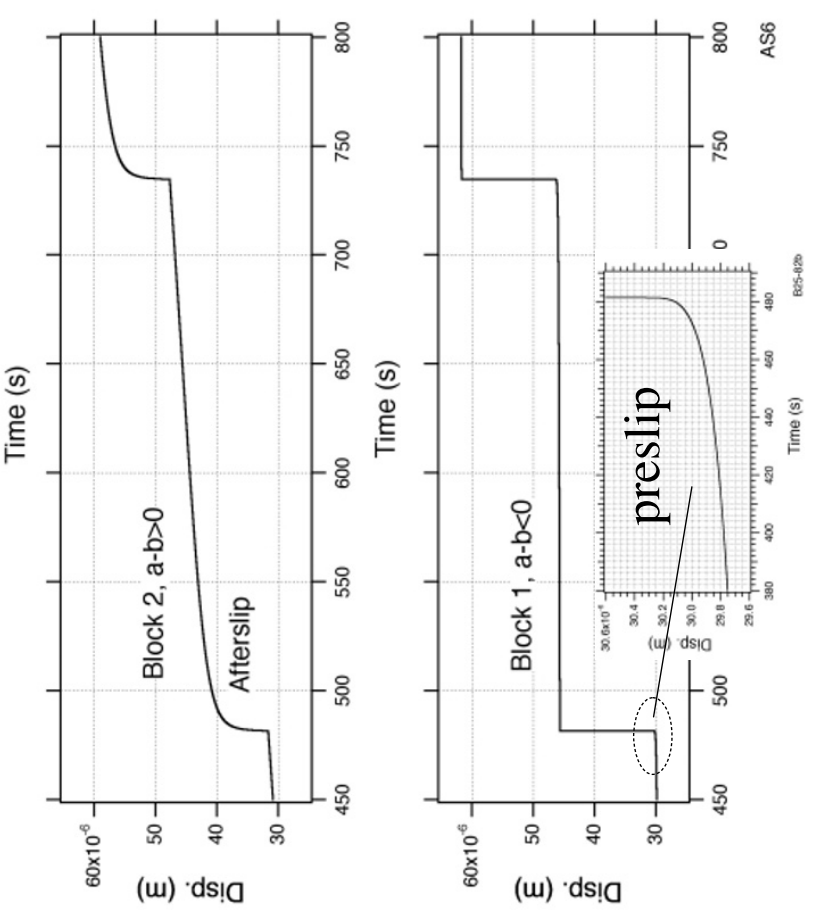

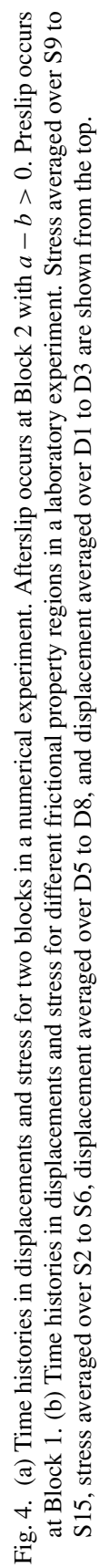




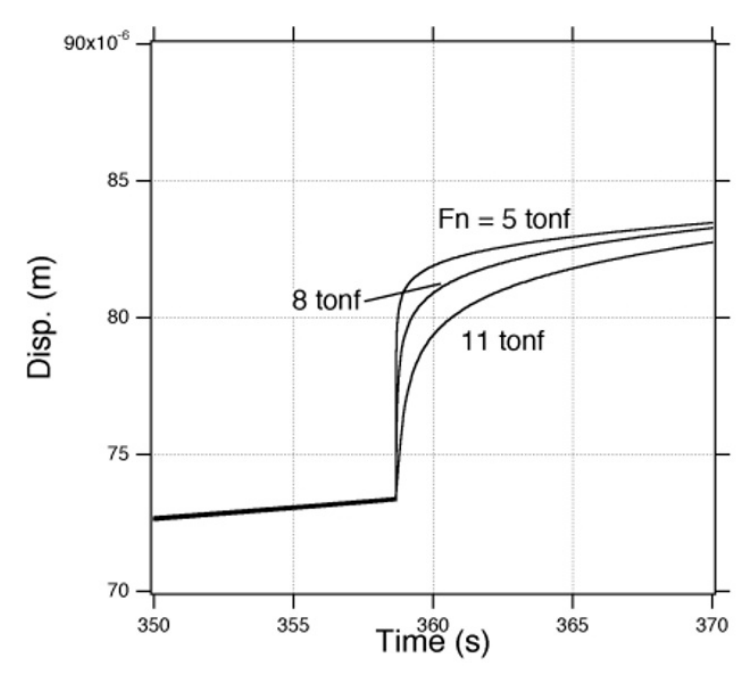

(a)

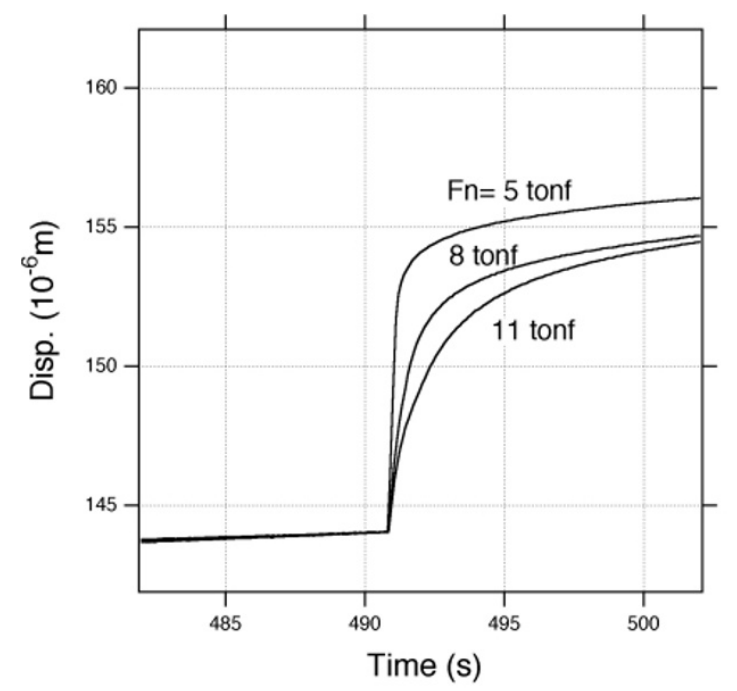

Fig. 5. Time histories in displacements for various normal forces in the velocity-strengthening region. (a) Result of numerical experiment. (b) Result of laboratory experiment. The displacement averaged over D5 to D8 is shown. As the normal force decreases, amount of the forced coseismic slip increases in both laboratory and numerical experiments.

local stress and local displacement measured along a fault plane. By having a stress information both on experiments and theoretical models, rather than mere phenomenological comparison of resulting slip history, we can be sure that the dynamics producing the observed complex behavior is the one that is represented in the model.

Although the simulation as in Fig. 4 shows no coseismic slip at Block 2, forced coseismic slip can be accompanied preceding afterslip when values of $(a-b) \sigma_{n}$ and/or $L$ are small, as pointed out by Marone et al. (1991) and Boatwright and Cocco (1996). We consider effect of different $\sigma_{n}$ applied to the positive $a-b$ region. In the laboratory experiments, the normal force applied to the positive $a-b$ (velocity strengthening) region was set to be 5, 8, 11 tonf. Figure 5(b) shows the displacement histories averaged over D5 to D8 for the different normal forces. As the normal force decreases, the effect like viscous resistance becomes smaller resulting in larger forced coseismic slip. This behavior is well reproduced by the numerical modeling assuming the same normal forces (Fig. 5(a)).

\section{Discussion and Conclusions}

Yoshida and Kato (2003) demonstrated that in the two block system associated with interaction of different frictional regions, frictional behavior could be differentiated into four regimes, as shown in Fig. 6. One of the two blocks is assumed to be act as an asperity with $a-b<0$ and $k<k_{c}$ for generating cyclic dynamic events. If the system does not include asperity, the system ultimately leads to steady state sliding, and various slip modes do not appear.

The velocity-weakening region with $a-b<0$ is categorized into regimes 1,2 , and 3 . Regime 1 with $k<k_{c}$ corresponds to asperity. During an interseismic period, the asperity is strongly locked, and just before dynamic event, preslip can occur as shown in Figs. 2(b) and 4(a). The asperity has potential to lead the system to instability. In regime $2, k$ is slightly greater than $k_{c}$, close to stability transition. In the early stage of an interseismic period, this region is locked, and stress increases there. When the stress approaches nearly steady state stress, episodic aseismic slip occurs. Behavior in regime 3 , where $k$ is sufficiently larger than $k_{c}$, is similar to that in regime 2, except that the slip smoothly converges to a steady state mode without oscillation. Regimes 1 to 3 have a locked stage with accumulating stress. On the other hand, regime 4 with $a-b>0$ has no locked stage. Instead abrupt stress loading is provided by dynamic slip at the adjacent asperity, and then afterslip follows with relaxation of the stress. After the stress is released to a steady state level, steady state slip continues. In this regime, forced dynamic slip can occur if $a-b$ takes a small value.

When the two block are asperities with different strength,

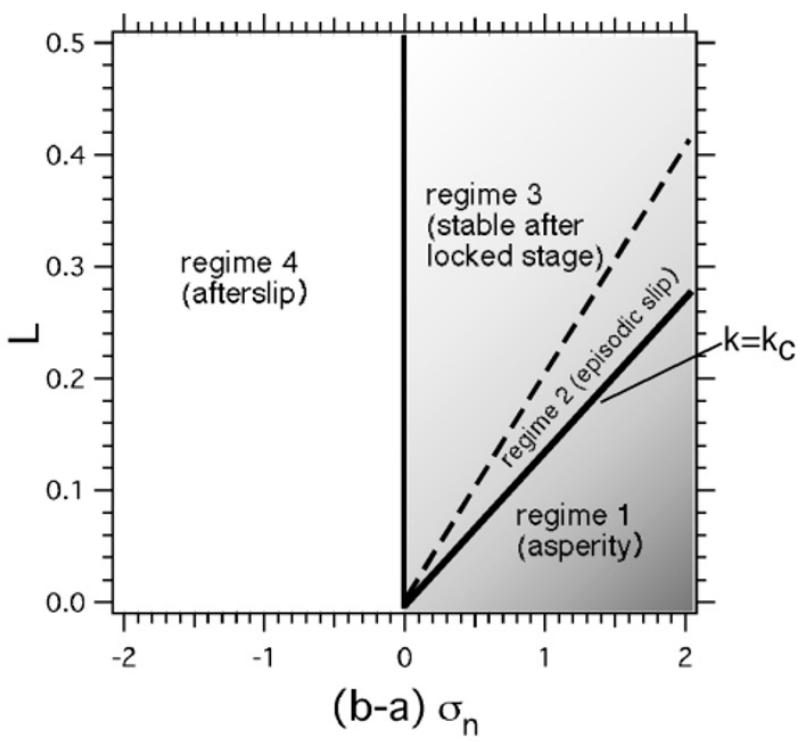

Fig. 6. Various slip modes depending on frictional parameters (after Yoshida and Kato, 2001). 
single asperity failure and double asperity failure occurs as denoted by laboratory experiments (Yoshida and Kato, 2001). During the single asperity failure, a weaker asperity ruptures alone, and the stronger asperity plays a role as a barrier to stop rupture propagation. This mechanism may be a plausible explanation of the rupture process in the 1994 Sanriku-Haruka-oki earthquake, in which slip occurred at one of more than two asperities that ruptured in the 1968 Tokachi-oki earthquake (Nagai et al., 2001).

In this paper, we observed afterslip in a velocitystrengthening region both in large-scale biaxial experiments and in numerical experiments using a two-block model. The numerical experiments can reproduce quantitatively the behavior seen in the laboratory experiments, including the effect of the normal stress to the forced coseismic slip.

A thin Teflon sheet was inserted along half section of the fault resulting in velocity-strengthening $(a-b>0)$. Measurement of local displacements and shear stresses at many points along the fault showed that afterslip occurred with gradual stress relaxation in the velocity-strengthening region. We also considered a two-degree-of-freedom blockspring model, in which two blocks (Block 1 and Block 2) are connected by a liner spring and driven by a slowly moving driver. The friction on each block was assumed to obey rate- and state-dependent friction law. When $a-b$ was assumed to be negative for Block 1, and positive for Block 2, afterslip occurred at Block 2. The numerical experiment can quantitatively reproduce the behavior observed in the laboratory experiment by adjusting frictional parameters.

Acknowledgments. We would like to thank J. Schmittbuhl and another anonymous reviewer for very useful comments. This research was supported by JSPS grant 14540392 .

\section{References}

Bürgmann, R., M. G. Kogan, V. E. Levin, C. H. Scholz, R. V. King, and G. M. Steblov, Rapid aseismic moment release following the 5 December, 1997 Kronotsky, Kamchatka, earthquake, Geophys. Res. Lett., 28, 13311334, 2001.

Boatwright, J. and M. Cocco, Frictional constraints on crustal faulting, $J$. Geophys. Res., 101, 13,895-13,909, 1996.

Dieterich, J. H., Modeling of rock friction: 1. Experimental results and constitutive equations, J. Geophys. Res., 84, 2161-2168, 1979.

Dieterich, J. H. and B. D. Kilgore, Direct observation of frictional contacts: New insights for state-dependent properties, Pure Appl. Geophys., 143, 283-302, 1994.

Dragert, H., K. Wang, and T. S. James, A silent slip event on the deeper Cascadia subduction interface, Science, 292, 1525-1528, 2001.

Freymueller, J., C. Zweck, H. Flethcer, S. Hreinsdottir, S. C. Cohenm, and M. Wyss, The great Alaska 'earthquake' of 1998-2001, EOS Trans. Am. Geophys. Un., 82, 2001.

Hirose, H., K. Hirahara, F. Kimata, N. Fujii, and S. Miyazaki, A slow thrust slip event following the 1996 Hyuga-nada earthquakes beneath the Bungo channel, southwest Japan, Geophys. Res. Lett., 26, 3237-3240, 1999.

Huang, J. and D. L. Turcotte, Are earthquakes an example of deterministic chaos?, Geophys. Res. Lett., 17, 223-226, 1990.

Kato, N. and T. Hirasawa, A numerical study on seismic coupling along subduction zones using a laboratory-derived friction law, Phys. Earth Planet. Interiors, 102, 51-68, 1997.

Kimata, F., N. Fujii, and K. Hirahara, Slow slip event detected from vertical movements by leveling and line length changes by EDM at the Tokai region in 1987, Progr. Abstr. Seism. Soc. Jpn., A41, 2001.

Lowry, A. R., K. M. Larson, V. Kostoglodov, and R. Bilham, Transient fault slip in Guerreri, southern Mexico, Geophys. Res. Lett., 28, 3253-3756, 2001.

Marone, C. J., C. H. Scholtz, and R. Bilham, On the mechanics of earthquake afterslip, J. Geophys. Res., 96, 8441-8452, 1991.

Nagai, R., M. Kikuchi, and Y. Yamanaka, Comparative study on the source processes of recurrent large earthquakes in Sanriku-oki region: the 1968 Tokachi-oki earthquake and the 1994 Sanriku-oki earthquake, Zisin, 54, 267-280, 2001 (in Japanese with English abstract).

Nussbaum, J. and A. Ruina, A two-degree-of freedom earthquake model with static/dynamic friction, Pure Appl. Geophys., 125, 629-656, 1987.

Ozawa, S., M. Murakami, M. Kaidzu, T. Tada, T. Sagiya, Y. Hatanaka, H. Yarai, and T. Nishimura, Detection and monitoring of ongoing aseismic slip in the Tokai region, central Japan, Science, 298, 1009-1012, 2002.

Perfettini, H. and J.-P. Avouca, Postseismic relaxation driven by brittle creep: A possible mechanism to reconcile geodetic measurements and the decay rate of aftershocks, application to the Chi-Chi earthquake, Taiwan, J. Geophys. Res., 109, doi:10.1029/2003JB002488, 2004.

Reilinger, R. E., S. Ergintav, R. Burgmann, S. McClusky, O. Lenk, A. Barka, O. Gurkan, L. Hearn, K. L. Feigl, R. Cakmak, B. Aktug, H. Ozener, and M. N. Toksoz, Coseismic and postseismic fault slip for the 17 August 1999, M=7.5, Izmit, Turkey earthquake, Science, 289, 1519-1524, 2000.

Rice, J. R., Spatio-temporal complexity of slip on a fault, J. Geophys. Res., 98, 9885-9907, 1993.

Ruina, A., Slip instability and state variable friction laws, J. Geophys. Res., 88, 10,359-10,370, 1983.

Sagiya, T., Interplate coupling in the Kanto district, central Japan, and the Boso Peninsula silent earthquake in May 1996, PAGEOPH, 2003 (submitted).

Scholz, C. H., The Mechanics of Earthquake and Faulting, 433 pp., Cambridge Univ. Press, New York, 1990.

Stuart, W. D., Forecast model for great earthquakes at the Nankai trough subduction zone, Pure Appl. Geophys., 126, 619-641, 1988.

Tse, S. T. and J. R. Rice, Crustal earthquake instability in relation to the depth variation of frictional slip properties, J. Geophys. Res., 91, 94529472, 1986.

Yagi, Y., M. Kikuchi, and T. Nishimura, Co-seismic slip, postseismic slip, and largest aftershock associated with the 1994 Sanriku-haruka-oki, Japan, earthquake, Geophys. Res. Lett., 30, 2177, doi:10.1029/2003GL018189, 2003.

Yoshida, S. and A. Kato, Single and double asperity failures in a large-scale biaxial experiment, Geophys. Res. Lett., 28, 451-454, 2001.

Yoshida, S. and N. Kato, Episodic aseismic slip in a two-degree-of-freedom block model, Geophys. Res. Lett., 30, 1681, doi:10.1029/2003GL017439, 2003.

S. Yoshida (e-mail: shingo@eri.u-tokyo.ac.jp), A. Kato, N. Kato, and M. Nakatani 